RESPIRATORY INFECTION

\title{
Impairment of $\beta$ chemokine and cytokine production in patients with HIV related Pneumocystis jerovici pneumonia
}

\author{
D Israël-Biet, H Esvant, A M Laval, J Cadranel
}

Thorax 2004;59:247-251. doi: 10.1136/thx.2003.013763

See end of article for authors' affiliations

\section{Correspondence to:}

Professor D Israël-Biet,

Service de Pneumologie,

Hôpital Européen Georges

Pompidou, 20 rue Leblanc,

75015 Paris, France;

dib.laennec@invivo.edu

Received 31 July 2003

Accepted

13 November 2003

\begin{abstract}
Background: Pneumocystis jerovici pneumonia (PJP) remains a frequent opportunistic infection in HIV infected patients which markedly upregulates HIV replication by mechanisms so far poorly elucidated. PJP triggers the production of proinflammatory mediators with activating effects on HIV. However, antiinflammatory factors with inhibiting effects on HIV are normally produced in parallel. We postulated that an imbalance of mediators normally controlling HIV replication could underlie its marked increase during PJP.

Methods: The production of tumour necrosis factor $\alpha$ (TNF $\alpha$ ), interleukins IL-6 and IL-10, and $\beta$-chemokine by bronchoalveolar lavage (BAL) cells recovered from HIV infected patients with and without PJP was compared. The pulmonary viral load was determined and correlations with cytokine and chemokine production were examined.

Results: TNF $\alpha$ and IL-6 release was similar in patients with and without PJP but IL-10 and $\beta$-chemokine release was markedly lower in the PJP group (IL-10: $p<10^{-2}$, RANTES, MIP-1 $\alpha$ and MIP-1 $\beta: p<0.001$ ). The pulmonary viral load was markedly higher in patients with PJP $(p<0.001)$ and correlated negatively with levels of MIP-1 $\alpha$, RANTES and IL-10 in BAL fluid cells $(p<0.05)$.

Conclusion: Pulmonary IL-10 and $\beta$-chemokine production is markedly defective in HIV infected patients with PJP, while pulmonary TNF $\alpha$ and IL-6 levels are normal. The resulting excess of these latter factors, which are known to upregulate HIV replication, might contribute to the increase in pulmonary viral load and to the more rapid HIV disease progression observed in patients with PJP.
\end{abstract}

$\mathrm{H}$ IV related mortality and morbidity have fallen dramatically since the introduction of highly active antiretroviral therapy (HAART), but the incidence of Pneumocystis jerovici pneumonia (PJP) remains relatively stable. PJP is still the most common AIDS revealing opportunistic infection in patients unaware of their HIV seropositivity. PJP is an independent risk factor for HIV disease progression, partly because it triggers intense viral replication $^{1-7}$ through unknown mechanisms. ${ }^{8-10}$ Some inflammatory mediators known to upregulate HIV replication are produced during PJP and tuberculosis. ${ }^{11}{ }^{12}$ However, antiinflammatory mediators that potently inhibit HIV replication are normally produced both in vitro and in animal models. ${ }^{13-15}$ In vivo, HIV replication is tightly controlled by a balance between pro- and anti-inflammatory cytokines. ${ }^{16} 17$ An imbalance between these mediators during the course of PJP would lead to a failure to control HIV replication in the lung and to a net increase in viral load. This issue has never, to our knowledge, been investigated. However, clues to the mechanisms by which PJP upregulates viral replication could have important therapeutic implications, such as the use of specific biological response modifiers. We have therefore examined the HIV load and pro- and anti-inflammatory cytokine and chemokine production in patients with active PJP.

\section{METHODS}

\section{Study population}

Bronchoalveolar lavage (BAL) was performed as part as the routine work up of HIV seropositive patients with unexplained fever, whether or not they had pulmonary symptoms or infiltrative lung disease. Patients were informed that a part of the pathological specimens could be used for molecular analysis provided that a definitive pathological diagnosis was obtained on their BAL fluid samples. BAL was performed in the most affected lung segment identified by CT scanning. Specimens were examined microscopically for cytological abnormalities, fungi and parasites, and were cultured for bacteria (including mycobacteria), fungi, parasites and viruses. Protected brush specimens were also obtained from patients with purulent secretions or focal abnormalities. When standard staining revealed no pathogens, BAL fluid specimens were tested for $P$ jerovici and Toxoplasma gondii by immunofluorescence.

Forty patients were enrolled in this retrospective study between February 1995 and February 1997. The above procedures revealed isolated PJP in 23 patients and ruled out opportunistic lung infection in 17 patients with isolated fever. At the time of BAL, 15 patients were receiving one or two antiretroviral drugs and 25 patients were receiving no antiretroviral treatment. When possible, aliquots of cell free BAL supernatants were stored at $-80^{\circ} \mathrm{C}$ for HIV load assay.

Table 1 shows the age, sex, HIV transmission group, CD4 cell count, and antiretroviral treatment of the study patients and table 2 shows the BAL findings.

\section{Bronchoalveolar cell culture}

BAL fluid remaining after the diagnostic tests was centrifuged $\left(200 \mathrm{~g}, 4^{\circ} \mathrm{C}, 10 \mathrm{~min}\right)$ and the cell pellet was resuspended in RPMI 1640 culture medium (ATGC, Noisy le Grand, France). Cell were $>95 \%$ viable in the Trypan blue exclusion test. Cell density was adjusted to $1 \times 10^{6} / \mathrm{ml}$ in RPMI medium supplemented with 1\% FCS (Flow, Les Ulis, France), $1 \%$ glutamine, and $1 \%$ penicillin-streptomycin (GIBCO, BRL,

Abbreviations: IL, interleukin; MIP, macrophage inflammatory protein; PJP, Pneumocystis jerovici pneumonia; RANTES, regulated on activation normal T cell expressed and secreted; TNF, tumour necrosis factor 


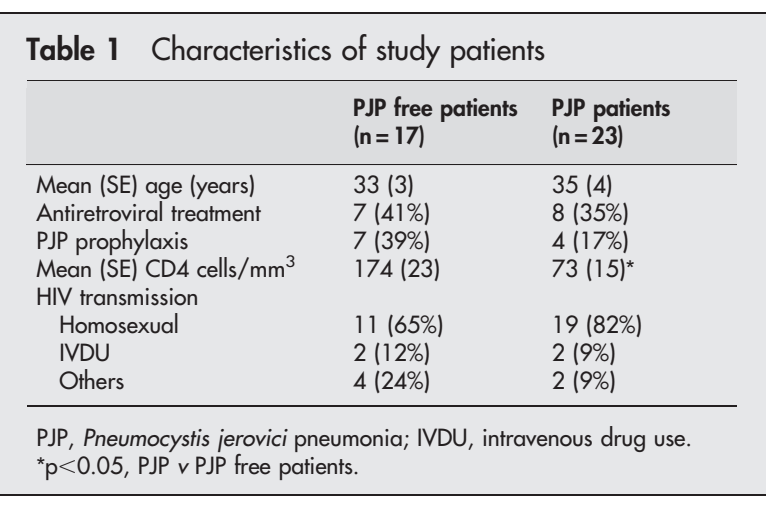

Eragny, France), and $10^{6}$ cells were cultured overnight in polypropylene tubes at $37^{\circ} \mathrm{C}$ with $5 \% \mathrm{CO}_{2}$. After $18-20$ hours, cell free culture supernatants were recovered and stored at $-80^{\circ} \mathrm{C}$ until analysis (within 18 months).

\section{Viral load assay}

The HIV-1 RNA level in cell free BAL fluid and in concomitant serum samples was measured with a commercial reverse transcription polymerase chain reaction (RT-PCR) kit (HIV Monitor, Roche Molecular Diagnostic Systems, Meylan, France; detection limit: 50 HIV-1 RNA copies/ml). To compensate for the dilution of epithelial lining fluid during the BAL procedure, alveolar viral load was corrected for the BAL fluid albumin concentration.

\section{Cytokine and chemokine assays}

Concentrations of cytokines and chemokines known to upregulate (TNF $\alpha$, IL-6) or downregulate (IL-10, RANTES, MIP- $1 \alpha$, MIP-1 $\beta$ ) HIV replication in vitro were measured in plasma and in BAL cell culture supernatants. Commercially available ELISA kits were used from R\&D Systems (Abingdon, UK) for RANTES, MIP- $1 \alpha$ and MIP- $1 \beta$ and from Biosource Europe (Nivelle, Belgium) for IL-6, IL-10 and $\mathrm{TNF} \alpha$. Results are expressed in $\mathrm{pg} / \mathrm{ml}$ plasma or culture supernatant. The detection limits of the kits are 10, 4, and $4 \mathrm{pg} / \mathrm{ml}$, respectively, for RANTES, MIP- $1 \alpha$ and MIP- $1 \beta$; and 2,1 , and $3 \mathrm{pg} / \mathrm{ml}$, respectively, for IL-6, IL-10 and TNF $\alpha$.

\section{Statistical analysis}

Results are expressed as median (range). Comparisons were made using the non-parametric Mann-Whitney $U$ test. Distributions of values were compared between groups using the $\chi^{2}$ test. Correlations were identified using the Spearman rank test. $\mathrm{p}$ values of $<0.05$ were considered significant.

\section{RESULTS}

\section{Viral load in BAL fluid and plasma}

Plasma viral load did not differ significantly between the patients with or without PJP: 63735 (5262-380 882) v 6534 (199-300 311) copies/ml, respectively. In contrast, the viral load in BAL fluid was markedly higher in patients with PJP than in those without, whether expressed per ml or per mg albumin: 2003 (366-19 013) v 277 (200-479) copies/ml, respectively $\quad(\mathrm{p}<0.05) ; \quad 47250 \quad(4690-322256) \quad v \quad 3519$ (1150-6746) copies/mg albumin, respectively $(\mathrm{p}<0.01)$. In the patients with PJP the viral load was, on average, 17 times higher in BAL fluid than in plasma: 47250 (4690-322 256) $v 2826 \quad(195-15$ 870) copies/mg albumin, respectively $(\mathrm{p}<0.001$; fig $1 \mathrm{~A})$ with a strong positive correlation between the two $(r=0.832, \mathrm{p}<0.001)$. In addition, the viral load was higher in BAL fluid than in plasma in all patients with PJP (fig 1B). Taken together, these data suggest local viral production, with alveolar lymphocytes possibly being the main source. Indeed, the viral load in the BAL fluid was
Table 2 Mean (SE) bronchoalveolar lavage cell composition (\%)

\begin{tabular}{lll}
\hline Cell type & $\begin{array}{l}\text { PJP free patients } \\
\text { (n= 17) }\end{array}$ & $\begin{array}{l}\text { PJP patients } \\
\text { (n= 23) }\end{array}$ \\
\hline Macrophages & $82(2)$ & $65(4)$ \\
Lymphocytes & $11(1)$ & $21(4)^{*}$ \\
PMN & $7(1)$ & $14(4)^{*}$ \\
\hline
\end{tabular}

PJP, Pneumocystis jerovici pneumonia; PMN; polymorphonuclear cells ${ }^{*} \mathrm{p}<0.05$, PJP $\vee$ PJP free patients.

positively correlated with the percentage of lymphocytes present in BAL fluid $(r=0.322, \mathrm{p}<0.05)$ and with no other cell type. In contrast, in subjects not infected with PJP the viral load did not differ significantly between BAL fluid and plasma: 3519 (1150-6746) v 272 (5-8385) copies/mg albumin, respectively. In the BAL fluid the viral load was not correlated with the amount of any cell type present.

\section{Proinflammatory cytokine and chemokine production by cultured alveolar cells}

Spontaneous release of the proinflammatory cytokines TNF $\alpha$ and IL- 6 by cultured BAL cells was similar in patients without or with PJP: 1880 (1000-2150) v 1840 (10772385) pg TNF $\alpha / \mathrm{ml}$, respectively (NS); 2295 (1492-3461) $v$ 2280 (1729-3521) pg IL-6/ml, respectively (NS; fig 2). By contrast, BAL cells from patients with PJP spontaneously produced far less IL-10 and $\beta$-chemokines than BAL cells from patients without PJP. On average, BAL cells from patients with PJP produced three times less IL-10 than cells from patients without PJP: 24 (5-85) v 75 (40-170) pg/ml $(\mathrm{p}<0.0 \mathrm{l}$; fig $3 \mathrm{~A})$; in addition, IL-10 production by BAL cells was undetectable in $11(58 \%)$ of the 19 tested subjects with PJP but was detected in all nine subjects tested who were free of PJP $\left(p<0.01, \chi^{2}\right.$ test $)$. The viral load in the BAL fluid correlated positively with IL-6 release from BAL fluid cells $(r=0.220, \mathrm{p}<0.05)$ and negatively with IL-10 release from BAL fluid cells $(r=0.380, \mathrm{p}<0.01)$.

Beta-chemokine production by alveolar cells also appeared to be markedly defective in the PJP group. RANTES production was six times lower in patients with PJP than in those without PJP: 58 (20-120) v 357 (105-720) pg/ml, respectively $(\mathrm{p}<0.001$; fig $3 \mathrm{~B})$ and was undetectable in five $(26 \%)$ of 19 subjects tested with PJP but was detectable in all nine patients tested without PJP. Likewise, MIP- $1 \alpha$ production was six times lower in subjects with PJP: 202 (90-355) $v$ 1117 (680-1725) pg/ml, respectively $(\mathrm{p}<0.001$; fig $3 \mathrm{C})$ and was below the detection limit in four of the $14(29 \%)$ tested subjects with PJP and in none of the nine PJP free subjects tested. Although MIP-1 $\beta$ was produced by BAL cells from all the subjects in both groups the levels were 10 times lower in the PJP group: 87 (19-370) v 900 (90-1220) pg/ml, respectively $(\mathrm{p}<0.001$; fig $3 \mathrm{D})$. Beta-chemokine production by BAL cells correlated negatively with the BAL fluid viral load in the overall population $(r=0.215, \mathrm{p}<0.05$ for both MIP- $1 \alpha$ and RANTES).

\section{Proinflammatory cytokine and chemokine plasma levels}

Plasma concentrations of TNF $\alpha$ and IL- 6 did not differ significantly between patients with or without PJP: 24 (3139) $v 23$ (3-119) pg TNF $\alpha / \mathrm{ml}$ and $13(2-201)$ v 3(2-56) pg IL-6/ml, respectively (NS; fig $4 \mathrm{~A}$ and $\mathrm{B}$ ). Plasma IL-10 concentrations were also similar in the two groups: 195 (45-485) v 205 (25-500) pg/ml (NS; fig 4C). In contrast, plasma $\beta$-chemokine levels were far lower in the PJP group than in the PJP free group, in keeping with the situation observed in the lung. The difference was highly significant 

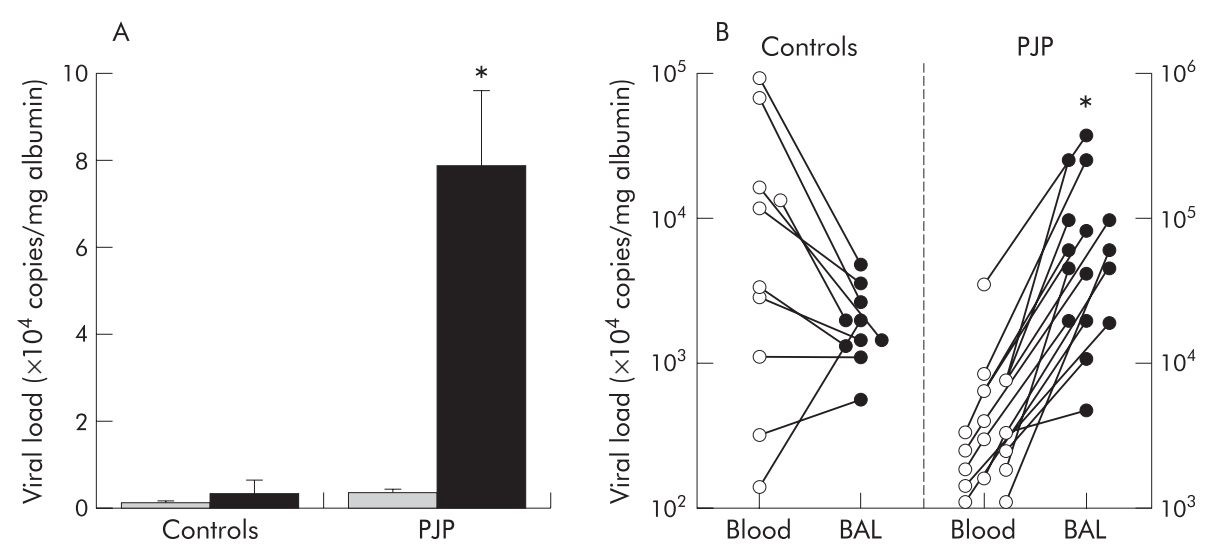

Figure 1 (A) HIV viral load in bronchoalveolar lavage (BAL) fluid (solid bars) and plasma (shaded bars) of the patient group with PJP and those free of PJP (controls). (B) Individual values of viral load of patients in the two groups (open circles, plasma levels; closed circles, BAL fluid); ${ }^{*} p<0.001$.

for RANTES (27 494 (19 114-38 763) v 47830 (9881209 930) $\mathrm{pg} / \mathrm{ml}$ in patients with and without PJP, respectively; $\mathrm{p}<0.001)$ and for MIP-1 $\beta$ (51 (21-75) $\vee 78$ (26153) $\mathrm{pg} / \mathrm{ml}$ in patients with and without PJP, respectively; $\mathrm{p}<0.002)$. MIP- $1 \alpha$ plasma levels tended to be lower in the PJP group (14 (6-40) v 20 (4-61) pg/ml; NS).

\section{DISCUSSION}

To our knowledge, this is the first study to show that increased HIV replication in the lungs of subjects with active PJP is linked to both strongly defective local $\beta$-chemokine release and an imbalance between proinflammatory and anti-inflammatory cytokine production. Opportunistic infections known to promote HIV replication ${ }^{1-3}$ include both active tuberculosis ${ }^{4} 9$ and PJP..$^{5-7}{ }^{10}$ In our study PJP was associated with a markedly higher viral load in BAL fluid but not in plasma, suggesting active pulmonary viral replication. In addition, the viral load in the BAL fluid and plasma were correlated strongly with each other in the PJP group $(p<0.001)$ but not in the PJP free control group, suggesting that viral production triggered in the lung by $P$ jerovici infection may make a strong contribution to the circulating viral load. The difference in pulmonary viral load between the two groups cannot be explained by different treatment strategies as similar proportions of patients were untreated at the time of the study $(78 \%$ and $72 \%$ of subjects with and without PJP, respectively), while the remainder were on single or dual agent antiretroviral regimens.

Several factors might be involved in the increased local virus production triggered by opportunistic pulmonary pathogens. Firstly, pathogen constituents could have a direct impact on HIV gene transcription. For example, Mycobacterium tuberculosis upregulates HIV replication both in vitro and in

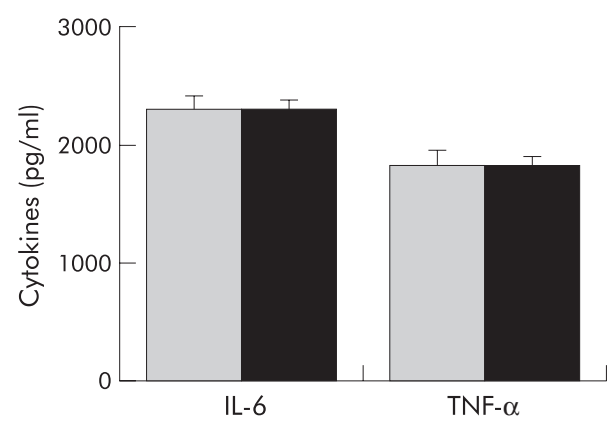

Figure 2 Production of IL- 6 and TNF $\alpha$ by alveolar cells in patients without PJP (shaded bars) and those with PJP (solid bars). vivo, ${ }^{4}{ }^{18}$ while Mycobacterium avium facilitates HIV infection of monocyte derived macrophages in vitro and is associated with pronounced viral replication in lymph nodes of HIV coinfected patients. ${ }^{19}$ To our knowledge, no direct effect of $P$ jerovici on HIV transcriptional mechanisms has been reported.

Opportunistic pathogens are also known to facilitate HIV replication indirectly by upregulating inflammatory mediators $^{9-11}$ such as TNF $\alpha$ and IL-6. ${ }^{20-23}$ Several in vitro studies have shown a direct effect of some $P$ jerovici constituents on TNF $\alpha$ release. ${ }^{24} 25$ We and others have shown that PJP is associated with marked production of proinflammatory cytokines, particularly TNF $\alpha$, in the human lung. ${ }^{126} \mathrm{~A}$ direct effect of proinflammatory cytokines on HIV production has been clearly established in vitro but not in vivo. ${ }^{26}{ }^{27}$ In this study we found that spontaneous TNF $\alpha$ and IL- 6 release by alveolar cells in vitro was similar in subjects with and without PJP. Thus, the markedly higher pulmonary viral load associated with PJP is probably due to other mechanisms, potentially including deficient IL-10 and $\beta$-chemokine production. Indeed, the balance between proinflammatory and anti-inflammatory cytokines is known to influence the replication of HIV critically. ${ }^{16}{ }^{17}$

IL-10 has complex effects on HIV infection. In vivo, high plasma levels of IL-10 have been linked to more rapid HIV disease progression. ${ }^{28}{ }^{29}$ In vitro, IL-10 inhibits HIV replication in macrophages ${ }^{30}$ but also cooperates with TNF $\alpha$ to activate HIV replication. ${ }^{31}$ The latter effect was also recently observed with latently infected T cells. ${ }^{32}$ IL-10 has complex regulatory effects on HIV expression which depend on its own concentration and on the presence of other HIV
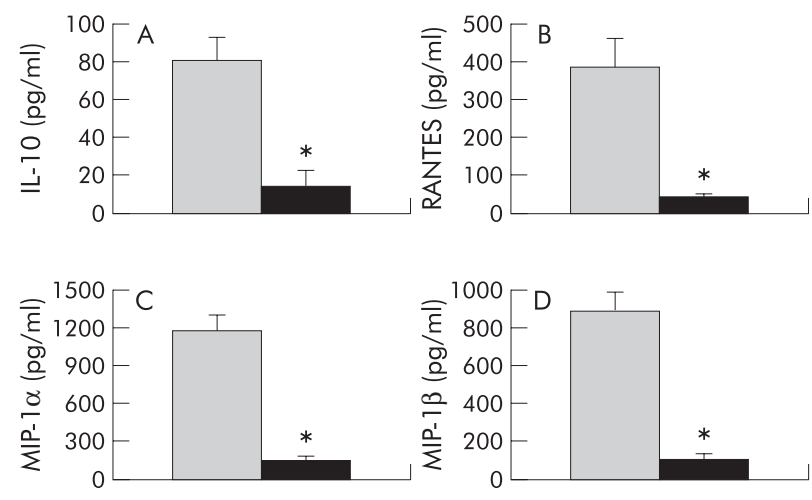

Figure 3 Production by alveolar cells of (A) IL-10, (B) RANTES, (C) MIP$1 \alpha$, and (D) MIP- $1 \beta$ in patients with PJP (solid bars) and those without PJP (shaded bars); ${ }^{*}<<0.001$. 

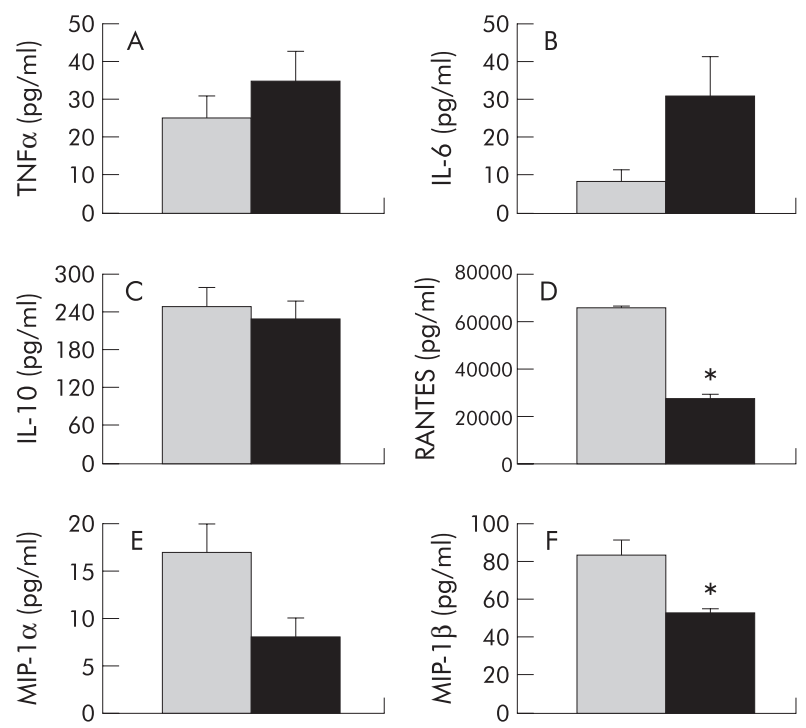

Figure 4 Plasma levels of (A) TNF $\alpha$, (B) IL- 6 and (C) IL-10 were comparable whereas those of (D) RANTES and (F) MIP-1 $\beta$ were significantly decreased ( ${ }^{*} p<0.002$ ) in patients with PJP (solid bars) compared with those free of PJP (shaded bars). Plasma levels of MIP- $1 \alpha$ (E) were lower in patients with PJP, although not significantly.

regulatory cytokines (particularly $\mathrm{TNF} \alpha$ and IL-6). ${ }^{33}$ We found a negative correlation between IL- 10 release by BAL cells and pulmonary viral load. IL-10 is a potent Th2 (antiinflammatory) cytokine which exerts negative regulatory effects on Thl (proinflammatory) cytokines by downregulating their synthesis, ${ }^{34}$ at least partly through specific mRNA destabilisation. ${ }^{35}$ IL-10 is strongly released in the lungs of experimental animals with PJP ${ }^{36}$ and also in humans. ${ }^{37}$ In our study, IL-10 levels were similar in the plasma of subjects with and without PJP, but were far lower in BAL fluid of subjects with PJP than in PJP free controls. We have no clear explanation for these findings. The strong influence of IL-10 gene promoter polymorphisms on the pattern of IL-10 production ${ }^{38}$ cannot explain the compartmentalisation of this defective production. Whatever the mechanism, the reduced capacity of alveolar cells to produce IL-10 during PJP would lead to a relative excess of Thl cytokines, which are produced during the acute phase of pneumonia and markedly upregulate virus replication.

The rate of HIV replication is also influenced by the balance between the inductive effects of some endogenous cytokines (TNF $\alpha$ and IL-1) and the suppressive effects of others; ${ }^{13} 173940$ RANTES is the most potent chemokine in this respect. ${ }^{41}$ In vivo, high circulating levels of MIP-1 $\beta$ have been linked to a lesser risk of HIV disease progression. ${ }^{42}$ It is therefore noteworthy that alveolar cells isolated from our patients with PJP displayed a markedly decreased capacity to release $\beta$-chemokines in culture, and that this release correlated negatively with the viral load in the BAL fluid. To our knowledge, this is the first report of such a defect in the context of PJP. Alveolar cells from HIV infected patients may exhibit impaired chemokine release on stimulation with lipopolysaccharide, a defect that correlates with the number of circulating CD4 cells. ${ }^{43}$ Intracellular MIP-1 $\beta$ accumulates in HIV infected subjects, with a negative relationship between the intracellular and secreted forms which is strongly linked to the degree of immunodeficiency. ${ }^{44}$ SCID mice challenged with $P$ jerovici show no pulmonary inflammatory response (partly owing to their inability to produce chemokines), while immune reconstitution leads to an intense response at the site of pulmonary infection together with strong local production of chemokines, particularly RANTES. ${ }^{14}$ The reduced capacity of our patients to generate an efficient chemokine response might therefore be due partly to their severe immunodeficiency. Alternatively, the defective chemokine production could be due to a direct effect of $P$ jerovici, in the same way as previously suggested in HIV infected patients with pleural tuberculosis." Betachemokines suppress HIV replication through competitive binding to their cell surface receptor (CCR5) which is also a key HIV co-receptor for macrophage-tropic virus entry, particularly in the lungs. ${ }^{45}$ Interestingly, HIV and some opportunistic pathogens upregulate the expression of chemokine receptors on infected alveolar macrophages. ${ }^{45}$ CCR5, for instance, is strongly upregulated during the course of $M$ tuberculosis infection, both in vivo and in vitro. ${ }^{15} 4647$ These effects are thought to be involved in the impact of tuberculosis on HIV infection. ${ }^{48}$ It would be interesting to examine CCR5 expression by BAL fluid cells from patients with PJP. Together with deficient chemokine production, CCR5 enhancement might leave a large number of HIV coreceptors unoccupied on lung cells. A concomitant imbalance in proinflammatory/anti-inflammatory cytokine production could result in transcriptional activation of HIV in latently infected cells and facilitate HIV infection of newly recruited cells. Moreover, activated macrophages are highly susceptible to classically T-tropic strains of HIV ${ }^{49}{ }^{50}$ owing to their strong expression of CCR3 and CXCR4. ${ }^{45}$ By a combination of these mechanisms, PJP might create one of the most propitious situations for HIV replication and dissemination.

\section{Authors' affiliations}

D Israël-Biet, H Esvant, A M Laval, Laboratoire d'Immunopathologie Pulmonaire, UPRES EA220, Université Paris V, Paris, France

D Israël-Biet, Service de Pneumologie, Hôpital Européen Georges Pompidou, Paris, France

J Cadranel, Service de Pneumologie et de Réanimation respiratoire, Hôpital Tenon, Paris, France

\section{REFERENCES}

1 Orenstein JM, Fox C, Wahl SM. Macrophages as a source of HIV during opportunistic infections. Science 1997;276:1857-61.

2 Wahl SM, Greenwell-Wild T, Peng G, et al. Co-infection with opportunistic pathogens promotes human immunodeficiency virus type 1 infection in macrophages. J Infect Dis 1999;179:S457-60.

3 Lawn SD, Roberts BD, Griffin GE, et al. Cellular compartments of human immunodeficiency virus type 1 replication in vivo: determination by presence of virion-associated host proteins and impact of opportunistic infection. J Virol 2000;74:139-45

4 Nakata K, Rom WN, Honda Y, et al. Mycobacterium tuberculosis enhances human immunodeficiency virus-1 replication in the lung. Am J Respir Crit Care Med 1997;155:996-1003.

5 Lu W, Israël-Biet D. Virion concentration in bronchoalveolar lavage fluids of HIV infected patients. Lancet 1993;342:298.

6 Israël-Biet D, Cadranel J, Even P. Human immunodeficiency virus production by alveolar lymphocytes is increased during Pneumocystis jerovici pneumonia. Am Rev Respir Dis 1993;148:1308-12.

7 Koziel H, Kim S, Reardon C, et al. Enhanced in vivo human immunodeficiency virus- 1 replication in the lungs of human immunodeficiency virus-infected persons with Pneumocystis jerovici pneumonia. Am J Respir Crit Care Med 1999; 160:2048-55.

8 Lederman M, Georges D, Kusner D, et al. Mycobacterium tuberculosis and its purified protein derivative activate expression of the human immunodeficiency virus. J Acquir Immune Defic Syndr 1994;7:727-33.

9 Toossi Z, Johnson JL, Kanost RA, et al. Increased replication of HIV-1 at sites of Mycobacterium tuberculosis infection: potential mechanisms of viral activation. $J$ Acquir Immune Defic Syndr 2001;28:1-8.

10 Shaunak S, Veryard C, Javan C. Severe Pneumocystis jerovici pneumonia increases the infectious titre of HIV-1 in blood and can promote the expansion of viral chemokines co-receptor tropism. J Infect 2001;43:3-6.

11 Garrait V, Cadranel J, Esvant H, et al. Tuberculosis generates a microenvironment enhancing productive infection of local lymphocytes by HIV. J Immunol 1997;159:2824-2830.

12 Israël-Biet D, Cadranel J, Beldjord K, et al. Tumor necrosis factor production in HIV seropositive subjects. Relationship with lung opportunistic infections and HIV expression in alveolar macrophages. J Immunol 1991;147:490-4.

13 Verani A, Scarlatti G, Comar M, et al. C-C chemokines released by lipopolysaccharide (LPS)-stimulated human macrophages suppress HIV-1 infection in both macrophages and T cells. J Exp Med 1997;185:805-16. 
14 Wright TW, Johnston CJ, Harmsen AG, et al. Chemokine gene expression during Pneumocytis jerovici-driven pulmonary inflammation. Infect Immun 1999;67:3452-60.

15 Fraziano M, Cappelli G, Santucci M, et al. Expression of CCR5 is increased in human monocyte-derived macrophages and alveolar macrophages in the course of in vivo and in vitro Mycobacterium tuberculosis infection. AIDS Res Hum Retrovir 1999;15:869-74.

16 Goletti D, Weissman D, Jackson R, et al. The in vitro induction of human immunodeficiency virus (HIV) replication in purified protein derivative-positive HIV-infected persons by recall antigen response to Mycobacterium tuberculosis is the result of a balance of the effects of endogenous interleukin-2 and proinflammatory and antiinflammatory cytokines. J Infect Dis 1998; 177:1332-8

17 Kinter A Ostrowski M, Goletti D, et al. HIV replication in CD4+ T cells of HIVinfected individuals is regulated by a balance between the viral suppressive effects of endogenous beta-chemokines and the viral inductive effects of other endogenous cytokines. Proc Natl Acad Sci USA 1996;93:14076-81.

18 Zhang $Y$, Nakata K, Weiden M, et al. Mycobacterium tuberculosis enhances human immunodeficiency virus-1 replication by transcriptional activation at the long terminal repeat. J Clin Invest 1995;95:2324-31.

19 Wahl S, Greenwell-Wild T, Hale-Donze H, et al. Permissive factors for HIV-1 infection of macrophages. J Leuk Biol 2000;68:303-10.

20 Poli G, Kinter A, Justement JS, et al. Tumor necrosis factor $\alpha$ functions in an autocrine manner in the induction of human immunodeficiency virus expression. Proc Natl Acad Sci USA 1990;87:782-5.

21 Tadmori W, Mondal D, Tadmori I, et al. Transactivation of human immunodeficiency virus type 1 long terminal repeat by cell surface tumor necrosis factor $\alpha$.J Virol 1991;65:6425-9.

22 Poli G, Bressler P, Kinter A, et al. Interleukin 6 induces human immunodeficiency virus expression in infected monocytic cells alone and in synergy with tumor necrosis factor $\alpha$ by transcriptional and posttranscriptional mechanisms. J Exp Med 1990;172:151-8.

23 Hoshino Y, Nakata K, Hoshino S, et al. Maximal HIV-1 replication in alveolar macrophages during tuberculosis requires both lymphocyte contact and cytokines. J Exp Med 2002; 195:495-505.

24 Vassallo R, Standing J, Limper A. Isolated Pneumocystis jerovici cell wall glucan provokes lower respiratory tract inflammatory responses. J Immunol 2000; 164:3755-63.

25 Benfield T, Van Steenwijk R, Nielsen T, et al. The major surface glycoprotein of Pneumocystis jerovici induces release and gene expression of interleukin-8 and tumor necrosis alpha in monocytes. Infect Immun 1997:65:4790-4.

26 Perenboom R, Saverwein R, Beckers $P$, et al. Cytokine profiles in bronchoalveolar lavage fluid and blood in HIV-seropositive patients with Pneumocystis jerovici pneumonia. Eur J Clin Invest 1997;27:333-9.

27 Kandil O, Fishman J, Koziel H, et al. Human immunodeficiency virus type 1 infection of human macrophages modulates the cytokine response to Pneumocystis jerovici. Infect Immun 1994;62:644-50.

28 Stylianou E, Aukrust P, Kvale D, et al. IL-10 in HIV infection: increasing serum IL-10 levels with disease progression. Down-regulatory effect of potent antiretroviral therapy. Clin Exp Immunol 1999;116:115-20.

29 Ostrowski M, Gu J, Kovacs C, et al. Quantitative and qualitative assessment of human immunodeficiency virus type 1 (HIV-1)-specific CD4+ T cell immunity to gag in HIV-1 infected individuals with differential disease progression: reciprocal interferon-gamma and interleukin-10 responses. J Infect Dis 2001;184:1268-78.

30 Akridge R, Oyafuso L, Reed S. IL-10 is induced during HIV-1 infection and is capable of decreasing viral replication in human macrophages. J Immunol 1994; 153:5782-9.

31 Finnegan A, Roebuck K, Nakai B, et al. IL-10 cooperates with TNF-alpha to activate HIV-1 from latently and acutely infected cells of monocyte/ macrophage lineage. J Immunol 1996;156:841-51.
32 Rabbi M, Finnegan A, Al-Harti L, et al. Interleukin-10 enhances tumor necrosis-alpha activation of HIV-1 transcription in latently infected T cells. J Acquir Immune Defic Syndr Hum Retrovirol 1998; 19:321-31.

33 Weissman D, Poli G, Fauci A. IL-10 synergizes with multiple cytokines in enhancing HIV production in cells of monocytic lineage. J Acquir Immune Defic Syndr Hum Retrovirol 1995;9:442-9.

34 Moore K, de Waal Malefyt R, Coffman R, et al. Interleukin-10 and the interleukin-10 receptor. Annu Rev Immunol 2001;19:683-765.

35 Hamilton T, Ohmori Y, Tebo J, et al. Regulation of macrophage gene expression by pro-and anti-inflammatory cytokines. Pathobiology 1999;67:241-4.

36 Ruan S, Tate C, Lee J, et al. Local delivery of the viral interleukin-10 gene suppresses tissue inflammation in murine Pneumocystis jerovici infection. Infect Immun 2002;70:6107-13.

37 Denis M, Ghadirian E. Dysregulation of interleukin 8, interleukin 10 and interleukin 12 release by alveolar macrophages from HIV type 1-infected subjects. AIDS Res Hum Retrovir 1994;10:1619-27.

38 Shin HD, Winkler C, Stephens JC, et al. Genetic restriction of HIV-1 pathogenesis to AIDS by promoter alleles of IL10. Proc Natl Acad Sci USA 2000;97:14467-72.

39 Coffey MJ, Woffendin C, Phare SM, et al. RANTES inhibits HIV-1 replication in human peripheral blood monocytes and alveolar macrophages. Am J Physiol 1997;272:L1025-9.

40 Capobianchi MR, Ábbate I, Antonelli G, et al. Inhibition of HIV type 1 BaL replication by MIP-1alpha, MIP-1 beta, and RANTES in macrophages. AIDS Res Hum Retrovir 1998;14:233-40.

41 Vicenzi E, Alfano M, Ghezzi S, et al. Divergent regulation of HIV-1 replication in PBMC of infected individuals by CC chemokines: suppression by RANTES MIP-1 alpha, and MCP-3, and enhancement by MCP-1. J Leuk Biol 2000;68:405-12

42 Ullum H, Cozzi Lepri A, Victor J, et al. Production of beta-chemokines in human immunodeficiency virus (HIV) infection: evidence that high levels of macrophage inflammatory protein-1 beta are associated with a decreased risk of HIV disease progression. J Infect Dis 1998;177:331-6.

43 Aung $\mathrm{H}, \mathrm{McKenna} \mathrm{S}$, Ketoff $\mathrm{N}$, et al. Dysregulation of beta-chemokines in the lungs of HIV-1-infected patients. J Acquir Immune Defic Syndr 2001;26:304-14.

44 Tartakovsky B, Turner D, Vardinon N, et al. Increased intracellular accumulation of macrophage inflammatory protein 1 beta and its decreased secretion correlate with advanced HIV disease. J Acquir Immune Defic Syndr 1999;20:420-2.

45 Worgall S, Connor R, Kaner RJ, et al. Expression and use of human immunodeficiency virus type 1 coreceptors by human alveolar macrophages. $J$ Virol 1999;73:5865-74

46 Manyanja-Kizza H, Wajia A, Wu M, et al. Activation of beta-chemokines and CCR5 in persons infected with human immunodeficiency virus type 1 and tuberculosis. J Infect Dis 2001;183:1801-4.

47 Shalekoff S, Pendle S, Hohnson D, et al. Distribution of the human immunodeficiency virus coreceptors CXCR4 and CCR5 on leukocytes of persons with human immunodeficiency virus type 1 infection and pulmonary tuberculosis: implications for pathogenesis. J Clin Immunol 2001;21:390-401.

48 Toossi Z, Manyanja-Kizza H, Hirsch C, et al. Impact of tuberculosis (TB) on HIV-1 activity in dually infected patients. Clin Exp Immunol 2001;123:233-8.

49 Bakri Y, Amzazi S, Mannioui A, et al. The susceptibility of macrophages to human immunodeficiency virus type $1 \mathrm{X} 4$ isolates depends on their activation state. Biomed Pharmacother 2001;55:32-8.

50 Bakri Y, Mannioui A, Ylisastigui L, et al. CD40-activated macrophages become highly susceptible to $\mathrm{X} 4$ strains of human immunodeficiency virus type 1. AIDS Res Hum Retrovir 2002;18:130-13. 